livraisons

d'Histoire

de l'Architecture

\section{Livraisons de l'histoire de l'architecture}

42 | 2021

2001-2021 / numéro anniversaire

\title{
Dominique Hervier et Eva Renzulli (dir.), André Chastel, portrait d'un historien de l'art (1912-1990). De sources en témoignages
}

Avec la participation de Sébastien Chauffour, Sophie Derrot, Florence Descamps et Pierre Vaisse, préface de Maryvonne de Saint-Pulgent, Paris, Comité d'histoire du ministère de la Culture/La Documentation française, coll. Travaux et documents, 2020, $456 \mathrm{p}$.

Isabelle Chave

\section{(e) OpenEdition}

\section{Édition électronique}

URL : https://journals.openedition.org//ha/3408

DOI : $10.4000 /$ /ha.3408

ISSN : 1960-5994

Éditeur

Association Livraisons d'histoire de l'architecture - LHA

\section{Référence électronique}

Isabelle Chave, « Dominique Hervier et Eva Renzulli (dir.), André Chastel, portrait d'un historien de l'art (1912-1990). De sources en témoignages », Livraisons de l'histoire de l'architecture [En ligne], 42 | 2021, mis en ligne le 11 décembre 2021, consulté le 11 décembre 2021. URL : http:// journals.openedition.org//ha/3408; DOI : https://doi.org/10.4000/lha.3408

Ce document a été généré automatiquement le 11 décembre 2021.

Tous droits réservés à l'Association LHA 


\section{Dominique Hervier et Eva Renzulli (dir.), André Chastel, portrait d'un historien de l'art (1912-1990). De sources en témoignages}

Avec la participation de Sébastien Chauffour, Sophie Derrot, Florence Descamps et Pierre Vaisse, préface de Maryvonne de Saint-Pulgent, Paris, Comité d'histoire du ministère de la Culture/La Documentation française, coll. Travaux et documents, 2020, $456 \mathrm{p}$.

\section{Isabelle Chave}

1 Le Comité d'histoire du ministère de la Culture a accueilli, en 2020, dans sa collection « Travaux et documents » un $42^{\mathrm{e}}$ volume passionnant, traçant le portrait d'un historien d'art exceptionnel, grâce à la conjugaison des archives orales et des sources écrites. Depuis sa création en 1993, le Comité a mené à bien une quinzaine de recueils thématiques ou monographiques de témoignages oraux (hauts fonctionnaires, conservateurs de l'Inventaire, architectes, universitaires...), mais aucune de ces campagnes n'avait eu, comme celle-ci, pour objet principal l'histoire de l'art: il s'agissait naturellement de marquer le 30e anniversaire du décès d'André Chastel.

2 C'est en 2012 que le projet Chastel, pour le centenaire de sa naissance, est formellement inscrit dans la programmation du Comité d'histoire, dans la perspective de publier à terme cette collecte d'archives orales à la manière d'un portrait de l'historien d'art: celui d'un André Chastel tour à tour pédagogue, entrepreneur, savant, écrivain, chroniqueur... L'ouvrage final présente, dans une approche très vivante et incarnée, toute la carrière de l'historien de l'art depuis ses débuts. Cette somme résulte d'un programme d'archives orales conduit de manière exemplaire, dont la teneur est accessible en ligne sur le site du Comité d'histoire abrité par le ministère de la Culture ${ }^{1}$. La collecte initiale d'archives orales autour de cette personnalité majeure s'est enrichie d'un programme de recherche sur André Chastel, historien de l'art et acteur public, croisant archives écrites (bibliothèque de l'Inha et Centre André-Chastel), et 
témoignages oraux rétrospectifs. Intégralement accompagnée par Florence Descamps, la collecte a eu pour cadre un partenariat avec la bibliothèque de l'Institut national d'histoire de l'art (2014) et une convention avec l'École nationale des chartes (2015); elle a aussi reçu l'appui de l'École pratique des hautes études (programme Histara). Le chantier a été confié à Dominique Hervier, historienne de l'art, conservateur général honoraire du patrimoine et ancienne élève d'André Chastel, et Eva Renzulli, docteur en histoire de l'art et chargée de conférences à l'École pratique des hautes études.

3 La trentaine d'acteurs interviewés ${ }^{2}$ ont livré leurs témoignages à la fois sur André Chastel lui-même et sur ces années 1950-1980 vécues dans son compagnonnage. Les heures d'entretiens, radiophoniques ou filmés, accordées par l'historien de l'art de son vivant, les collections de témoignages oraux constituées pour l'histoire de l'art, telle la collection ministérielle "Les inventeurs de patrimoines", et les archives privées écrites d'André Chastel et de son entourage font l'objet d'un examen critique et détaillé, pour évaluer leur apport, leur degré de subjectivité ou leur complétude. Du point de vue formel, dans l'écriture de l'histoire et le travail biographique, André Chastel, portrait d'un historien de l'art tire son intérêt de cette intrication des divers types de sources recueillies et exploitées en outre: manuscrits, sources imprimées, témoignages oraux, entretiens audiovisuels, pièces de correspondance avec des conservateurs et des historiens de l'art ou du patrimoine du monde entier - des correspondants estimés à plus de deux mille au total...

Organisé en quatre parties, l'ouvrage s'ouvre sur la fabrique du projet testimonial, puis éditorial, avec un propos méthodologique et heuristique. Il évoque naturellement la fondation du ministère de la Culture par André Malraux, puis ses ministres successifs ; aborde la politique de protection des monuments historiques; rappelle la genèse de l'Inventaire général des monuments et des richesses artistiques de la France et de ses entités sur tout le territoire national. Il rend compte du développement des services culturels et patrimoniaux, de leurs outils scientifiques et d'expertise et de leurs actions d'éducation artistique, mais aussi de la place de l'architecture et de l'urbanisme dans les Trente Glorieuses. Depuis sa situation dans les années 1950, avec un constat très bien dressé par Pierre Vaisse, l'élan de l'enseignement universitaire et académique de l'histoire de l'art en France est parfaitement décrit. Les coordinateurs du volume établissent clairement aussi les thèmes que l'ouvrage, quoique très dense déjà, n'a pas permis de traiter, en raison de la plus faible représentation de témoignages oraux en rapport (Seconde Guerre mondiale, construction européenne, instauration de la $V^{e}$ République, Mai 68...). Le rayonnement des travaux d'André Chastel à l'international mériterait, lui aussi, un apport complémentaire. La deuxième partie de l'ouvrage est consacrée à l'enseignement dispensé par l'historien d'art, comme professeur et directeur de recherches (École pratique des hautes études, Sorbonne, Collège de France), et à sa contribution au développement de la recherche, à travers le Centre de recherches sur l'histoire de l'architecture moderne (Crham / CNRS). Dans une troisième partie, intitulée "Une vie pour le Patrimoine », le lecteur trouvera une présentation commentée des témoignages recueillis sur l'Inventaire général et sur les Monuments historiques, les secteurs sauvegardés et la Commission des monuments historiques. Enfin, la quatrième partie, sous le titre "Les clés de la notoriété et du pouvoir ", aborde l'esprit cosmopolite et la culture européenne d'André Chastel, ses activités de journaliste (Le Monde) et d'éditeur (Revue de l'art), autant de canaux utilisés pour faire connaître et reconnaître sa discipline. Tout au long de l'ouvrage, Dominique Hervier et Eva Renzulli, ainsi que les autres contributeurs (Sébastien Chauffour, Sophie Derrot, 
Florence Descamps et Pierre Vaisse), ont su émailler le texte de chaque chapitre de nombreuses citations et rendre compte des réseaux d'amitié établis par l'historien d'art autant que des réactions parfois sévères suscitées par sa forte personnalité, quoique charismatique.

L'ouvrage s'achève par de multiples annexes, à commencer par un cahier d'illustrations particulièrement attachant, des années 1920 aux années 1970, qui figure les cercles intellectuels et amicaux d'André Chastel (réunions d'associations professionnelles, voyages d'étudiants, stages, inaugurations de commissions régionales de l'Inventaire général, excursions, congrès de sociétés savantes, colloques internationaux). Suivent les portraits d'une quinzaine des témoins questionnés, des repères chronologiques, des notices biographiques sommaires des vingt-six témoins de la campagne d'archives orales, les références des dossiers de correspondance à la bibliothèque de l'INHA (base de données Agorha), et une très utile chronologie pratique, indiquant les sujets des cours, des conférences et des séminaires dispensés par André Chastel à l'École pratique des hautes études (1951-1979), à l'Institut d'art et d'archéologie de la Sorbonne (1955-1970) et au Collège de France (1971-1984), reconstituée grâce à l'exploitation, la plus complète possible, des sources et des témoignages. Enfin, des références bibliographiques et index viennent clore cet hommage exceptionnel.

\section{NOTES}

1. Voir la rubrique «Les archives orales autour d'André Chastel », en ligne: https:// www.culture.gouv.fr/Nous-connaitre/Decouvrir-le-ministere/Histoire-du-ministere/

Evenements/Archives-orales/Andre-Chastel-vu-par-son-entourage (consulté le 7 novembre 2021).

2. Jean-Pierre Babelon, Françoise Boudon, Monique Chatenet, Bruno Foucart, Christoph Luitpold Frommel, Marc Fumaroli, Jean Guillaume, Françoise Hamon, Dominique Hervier, Bertrand Jestaz, Jean-Michel Leniaud, Françoise Levaillant, Christiane Lorgues, Claude Mignot, Jean-Marie Pérouse de Montclos, Monique Mosser, Christian Pattyn, Gérard Régnier dit Jean Clair, Pierre Rosenberg, Maryvonne de Saint-Pulgent, Willibald Sauerländer, Antoine et Dominique Schnapper, François Souchal, Bernard Toulier et Henri Zerner. 